\title{
Acid Resistance of Ternary Blended Nanosilica Concrete Incorporating Fly Ash and Alccofine
}

\author{
Avuthu Narender Reddy, T. Meena* \\ Department of Structural and Geotechnical Engineering, School of Civil Engineering, Vellore Institute of Technology, Vellore, \\ Tamilnadu, India
}

Received January 20, 2021; Revised February 23, 2021; Accepted March 23, 2021

\begin{abstract}
Cite This Paper in the following Citation Styles
(a): [1] Avuthu Narender Reddy, T. Meena, "Acid Resistance of Ternary Blended Nanosilica Concrete Incorporating Fly Ash and Alccofine," Civil Engineering and Architecture, Vol. 9, No. 2, pp. 500-506, 2021. DOI: 10.13189/cea.2021.090222.
\end{abstract}

(b): Avuthu Narender Reddy, T. Meena (2021). Acid Resistance of Ternary Blended Nanosilica Concrete Incorporating Fly Ash and Alccofine. Civil Engineering and Architecture, 9(2), 500-506. DOI: 10.13189/cea.2021.090222.

Copyright $(2021$ by authors, all rights reserved. Authors agree that this article remains permanently open access under the terms of the Creative Commons Attribution License 4.0 International License

\begin{abstract}
The use of industrial waste or byproducts as a replacement of cement leads to cost reduction, energy-saving, and is also eco-friendly. Studies reveal that the quaternary and ternary blended concrete may be superior in durability properties when compared with conventional concrete. With the expansion of the use of concrete structures in the sewage system, the corrosion effects of aggressive acid attacks on cement-based construction have gained more significance. The present study aims to investigate the acid resistance of M30 and M60 grades of concrete and the influence of the combination of fly ash, alccofine, and nanosilica in it. The combination of $25 \%$ fly ash, $10 \%$ alccofine and various percentages of nanosilica $(0.5 \%, 1 \%, 2 \%, 3 \%)$ have been tested for 28, 56, 90,180 days for acid resistance. From the result, it is seen that the concrete with a combination of fly ash, alccofine, and nanosilica showed better performance in resisting the acid attack on M30 and M60 grades of concrete based on percentage weight loss of specimens over different curing periods.
\end{abstract}

Keywords Fly Ash, Alccofine, Nanosilica, Acid Resistance

\section{Introduction}

The beneficial properties of concrete, strength and durability improve its role in the construction industry. It is commonly used worldwide in constructing buildings, bridges, dams, roads, etc. [1,10]. Concrete used for the sanitation plants, sanitary sewers, drainage ditches as well as other industrial structures, however, experiences a highly aggressive environment through exposure to acidic solutions, which poses the risk of concrete deterioration and threatens the service life of concrete components and consequently its overall structural performance [2, 8]. In general, the concrete made with Ordinary Portland Cement (OPC) does not exhibit high resistance towards acid attack due to the presence of a high amount of calcium hydroxide (portlandite) [3-5]. Therefore, several attempts have been done to enhance mechanical and durability properties by using different industrial waste by-products and supplementary cementitious materials in the concrete $[6,12]$. In recent years, some of the industrial by-products which are rich in silica and alumina content such as fly ash (FA), rice husk ash (RHA), ground granulated blast furnace slag (GGBS), silica fume (SF), alccofine $(\mathrm{AL})$, red mud, etc which are creating treat to the environment are being used as partial replacement of OPC in concrete [10-15].

Nanotechnology has drawn tremendous scientific attention in recent years, because of the various possible applications of nanometer-scale particles [16]. Nanotechnology is a new avenue in material science that could have a significant effect on the environment. For the construction sector, nanotechnology is described as key for controlling properties at the nanometer-scale which can bring advancement in cement based composites with unique mechanical, durability and thermal properties using scientific principles [24]. Extensive research is 
being performed to enhance the efficiency of building materials and to produce durable concrete for the construction industry through the implementation of nanomaterials $[25,29,30]$. The nanomaterials like nanosilica (NS) possess high pozzolanic nature and can significantly improve the properties of concrete in all aspects. It was found that using NS in concrete can accelerate the pozzolanic reaction and forms more C-S-H gel in the concrete and NS also can improve the density of the interfacial transition zone (ITZ) of concrete by filling the pores [26,27].

The OPC can be replaced with a combination of one or two or three SCM to form a binary, ternary and quaternary blended concrete mix. Nandhini (2020) [1] investigated the effect of NS on durability properties of self-compacting concrete and concluded that the concrete containing $2 \%$ NS exhibits high durability when compared with other mixes. The microstructure and particle packing density have been improved by the addition of NS, resulting in improvement of strength and better durability when compared with conventional concrete. Mahmoud, M. et al. (2019) [2], mixed fly ash, slag with nanosilica with alkali activators for repairing the concrete structures affected by acidic media. From the results, they concluded that the combination of these materials improved the bond strength and resistance to mass loss in repair prototypes cured in a very aggressive $(10 \%)$ sulphuric environment. The mix containing a combination of fly ash with $10 \%$ slag and $6 \%$ nanosilica improved the acidic resistance with time. They also concluded that such combinations with alkali activators will be a viable option for repair applications in acidic environments. Swapnil B. Walzade (2016) [3] had led a test on M80 grade of cement by supplanting cement with a mix of FA and NS. From the results, he concluded that cement replacement with a combination of $3 \%$ NS and $20 \%$ FA showed maximum strength and maximum acid attack resistance when compared with all other mixes. Steve Wilben Macquarie Supit (2014) [4] has done an investigation into the durability of blended cement containing a combination of FA and NS. They also concluded that the combination of NS with FA led to an early pozzolanic reaction due to nanosilica's higher surface area and particle size. From the investigation, they concluded that the combination FA with NS significantly improved the compressive strength and showed high durability. From the SEM analysis, they concluded that the reaction between NS and $\mathrm{CH}$ might have happened and produced more $\mathrm{CSH}$ gel making the concrete denser which helped in reducing the capillary pores resulting in increased resistance to water and chloride permeability. M-Hong Zhang (2011) [6] had done an experimental investigation into mortars containing various percentages of nanosilica, from the result he concluded that the incorporation of $2 \%$ nanosilica reduced initial and final setting time and increased the compressive strength of mortars when compared to other mixes. P. R. Kalyana Chakravarthy (2017) [5] performed an experimental study by replacing cement with various percentages of alccofine and concluded that replacing cement with $16 \%$ alccofine had shown more strength when compared with different blend mixes for both 7 days and 28 days. He also concluded that by using alccofine the resistance against chemical and acid attacks improved significantly. Previous studies revealed that the tetranary or quaternary, and ternary blended concrete may present a high durability when compared with conventional concrete.

The present study aims to investigate the influence of a combination of FA, AL, NS forming a Ternary Blended Concrete (TBC) on acid resistance of concrete mixtures of M30 and M60 grade. The combination of $25 \%$ fly ash, $10 \%$ alccofine with various percentages of nanosilica $(0.5 \%, 1 \%, 2 \%, 3 \%)$ have been tested for $28,56,90,180$ days acid resistance.

\section{Materials}

53 grade OPC, class $\mathrm{F}$ type of $\mathrm{FA}, \mathrm{AL}$, and colloidal NS are used in all mixes. 53 grade OPC obtained from Zuari Dements Private Limited, Yerraguntla, Kadapa district, Andhra Pradesh having a specific gravity 3.1, initial and final setting time of $50 \mathrm{~min}$ and $450 \mathrm{~min}$, fineness modulus of $6.5 \%$ confining to IS $12269-2013$ [18] was used in the entire study. The class F fly ash with a specific gravity of 2.3, fineness modulus of $1.19 \%$ obtained from $\mathrm{N} T$ Rao Thermal Power station, Vijayawada (VTPS), confining to IS 3812-2013 [21] was used in the entire study. Alccofine having a specific gravity of 2.9, the particle size of 1.5 microns to 9 microns, acquired from Counto Microfine Products Pvt. Ltd confining to ASTM C989-1999 [28] was used in the entire study. Nanosilica is obtained from Beechem Chemicals Ltd, with a particle size of is $10-20 \mathrm{~nm}$, a specific gravity of 1.2 , and purity of $99 \%$ was used also in the entire study. Locally available river sand having a specific gravity of 2.6 , water absorption of $1.02 \%$ and fineness modulus of $2.7 \%$ was used as fine aggregate and locally available crushed stone passing through $20 \mathrm{~mm}$ sieve having a specific gravity of 2.781 , water absorption of $0.8 \%$ and fineness modulus of $7.2 \%$ confining to IS 383-2016 [19] was used as was used in the study. Normal tap water of $\mathrm{pH}$ value ranging between 7 and 8 available in the campus was used in the entire study and poly-carboxylic ether (PCE) type of chloride-free Superplasticizer confirming to ASTM C494-2017 [7] was used.

Notations in Table: GC: Grade of Concrete, MN: Mix Number, OPC: Ordinary Portland Cement Content, FA: Fly ash Content, AL: Alccofine Content, NS: Nanosilica Content. 
Table 1. Mix proportion

\begin{tabular}{|c|c|c|c|c|c|c|c|c|}
\hline GC & MN & $\begin{array}{c}\text { OPC } \\
\left(\mathrm{kg} / \mathrm{m}^{3}\right)\end{array}$ & $\begin{array}{c}\mathbf{F A} \\
\left(\mathrm{kg} / \mathrm{m}^{3}\right)\end{array}$ & $\begin{array}{c}\mathrm{AL} \\
\left(\mathrm{kg} / \mathrm{m}^{3}\right)\end{array}$ & $\begin{array}{c}\mathrm{NS} \\
\left(\mathrm{kg} / \mathrm{m}^{3}\right)\end{array}$ & $\begin{array}{c}\text { Fine Aggregate } \\
\left(\mathrm{kg} / \mathrm{m}^{3}\right)\end{array}$ & $\begin{array}{c}\text { Coarse Aggregate } \\
\left(\mathrm{kg} / \mathrm{m}^{3}\right)\end{array}$ & $\begin{array}{r}\text { Water } \\
\left(\mathrm{kg} / \mathrm{m}^{3}\right)\end{array}$ \\
\hline \multirow{6}{*}{ M30 } & $30 \mathrm{C} 1$ & 350.2 & - & - & - & 721.5 & 1273.8 & 150.5 \\
\hline & $30 \mathrm{~N} 0$ & 236.4 & 87.5 & 26.3 & - & 721.5 & 1273.8 & 150.5 \\
\hline & $30 \mathrm{~N} 0.5$ & 235.2 & 87.5 & 26.3 & 1.2 & 721.5 & 1273.8 & 150.5 \\
\hline & $30 \mathrm{~N} 1$ & 234.06 & 87.5 & 26.3 & 2.3 & 721.5 & 1273.8 & 150.5 \\
\hline & $30 \mathrm{~N} 2$ & 231.7 & 87.5 & 26.3 & 4.7 & 721.5 & 1273.8 & 150.5 \\
\hline & $30 \mathrm{~N} 3$ & 229.3 & 87.5 & 26.3 & 7.1 & 721.5 & 1273.8 & 150.5 \\
\hline \multirow{6}{*}{ M60 } & $60 \mathrm{C} 2$ & 540.1 & - & - & - & 625.5 & 1180.8 & 162.03 \\
\hline & $60 \mathrm{~N} 0$ & 364.5 & 135.02 & 40.5 & - & 625.5 & 1180.8 & 162.03 \\
\hline & $60 \mathrm{~N} 0.5$ & 362.7 & 135.02 & 40.5 & 1.8 & 625.5 & 1180.8 & 162.03 \\
\hline & $60 \mathrm{~N} 1$ & 360.9 & 135.02 & 40.5 & 3.6 & 625.5 & 1180.8 & 162.03 \\
\hline & $60 \mathrm{~N} 2$ & 357.3 & 135.02 & 40.5 & 7.3 & 625.5 & 1180.8 & 162.03 \\
\hline & $60 \mathrm{~N} 3$ & 353.7 & 135.02 & 40.5 & 10.9 & 625.5 & 1180.8 & 162.03 \\
\hline
\end{tabular}
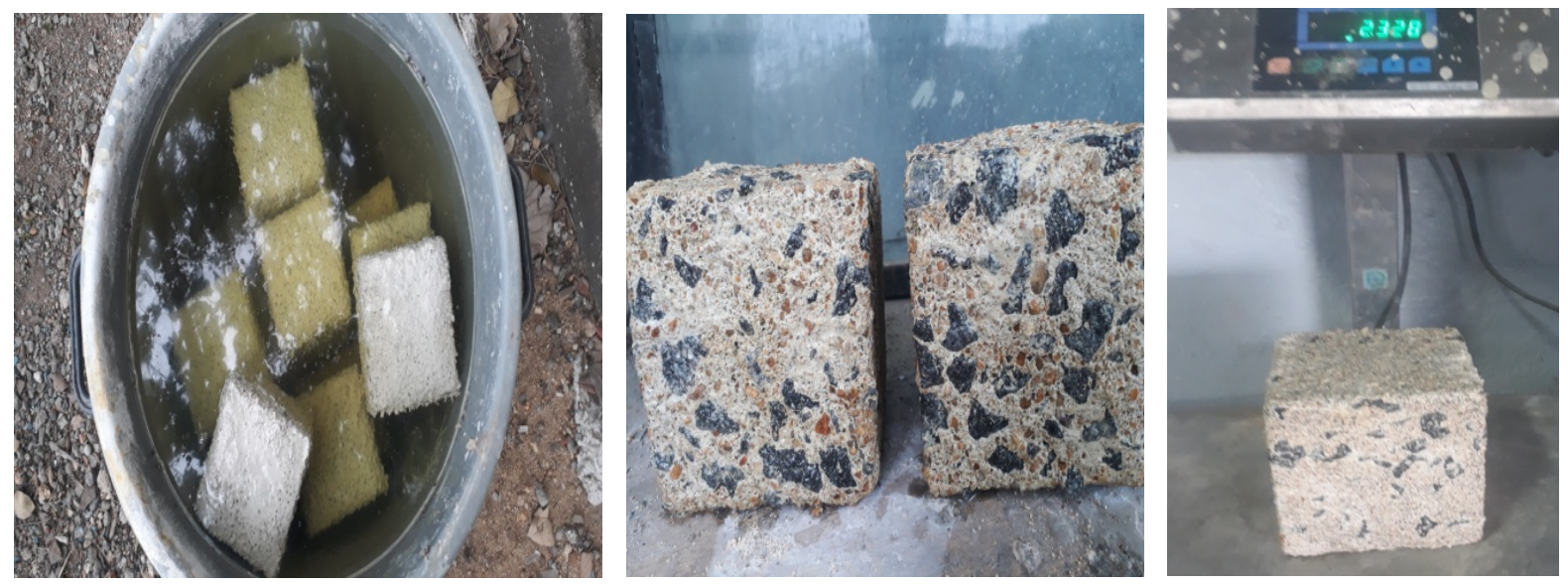

Figure 1. Specimens in acid solution and its testing

\section{Methodology}

All the ingredients, OPC, FA, AL, fine aggregate, and coarse aggregate were mixed throughly for 1-2 $\mathrm{min}$ in the dry state. The nanosilica used in the investigation was in a colloidal form so the percentage of nanosilica was added to half of the water; the PCE type of superplasticizer was mixed with another half of the water and mixed with other ingredients. They were mixed thoroughly until the mix obtained uniform colour. Totally 36 Cube specimens of size $100 \mathrm{~mm} \times 100 \mathrm{~mm} \times 100 \mathrm{~mm}$ were cast and de-molded after 24 hours. They were kept for curing in fresh water for 28 days. After 28 days the specimens were removed and allowed to surface dry for 2-3 hours. Then the weights of the specimens were noted as, $\mathrm{W}_{\text {Initial }}$ (Weight of specimen before immersing into the acid solution) and the specimens were kept in $5 \% \mathrm{H}_{2} \mathrm{SO}_{4}$ acid solution for acid exposure (The actual sensitivity of concrete to acid attack increases when the $\mathrm{pH}$ of the acid contact is lowered from 6.5. A pH of 6.5 to 5.5 is considered to be less exposure, a $\mathrm{pH}$ of 5.5 to 4.5 is considered to be severe exposure, and a $\mathrm{pH}$ of less than 4.5 considered to be very severe exposure [31], here we have consider for very severe exposure and by diluting the
$5 \%$ concentrated $\mathrm{H}_{2} \mathrm{SO}_{4}$ in water have achieved the $\mathrm{pH}$ of 4 and it was maintained throughout the investigation). The specimens were removed periodically and weight loss of the specimen was measured until 180 days. The weight loss was measured for 28, 56, 90, and 180 days of acid exposure. Weight measurement was done using an electronic weighing balance having a precision of 4 . The specimens were again kept for curing in the acid solution immediately after the weight loss measurement as shown in the figure 1.

\section{Results and Discussion}

Concrete is an alkaline material and when it is attacked by sulphuric acid, the $\mathrm{Ca}(\mathrm{OH})_{2}$ reacts with it and forms first gypsum and then forms ettringite with calcium aluminium hydrate. This formation slowly increases the volume of solid-phase causing gradual disintegration of concrete. Previous studies on OPC-based concrete showed a highly deleterious effect of sulfuric acid on mass loss [1, $2,5]$. This is because the sulfuric acid reacts with $\mathrm{Ca}$ $(\mathrm{OH})_{2}$ and forms gypsum then reacts with calcium 
aluminium hydrates to form ettringite, which is an expansive salt, that deteriorates the concrete matrix $[3,4]$. A series of the combination of $25 \% \mathrm{FA}, 10 \% \mathrm{AL}$ and $0 \%$, $0.5 \%, 1 \%, 2 \%, 3 \%$ NS by weight as a replacement of cement for two different grades M30 and M60 had been prepared to find the acid resistance of concrete with the mineral admixtures. Weight loss is one way of reporting the concrete resistance to acidic attack. It is the most effective quantitative approach to measuring and evaluating the acid resistance of concrete mixtures.
Consequently weight loss was measured at each immersion period using the equation.

$$
\mathrm{WLP}=\left(\left(\mathrm{W}_{\text {Initial }}-\mathrm{W}_{\text {Saturated }}\right) /\left(\mathrm{W}_{\text {Initial }}\right)\right) \times 100
$$

where WLP is Weight Loss Percentage, $\mathrm{W}_{\text {Initial }}$ is Weight of specimen before immersing into the acid solution and $\mathrm{W}_{\text {saturated }}$ is Weight of specimen after removing it from acid solution periodically. The specimens were allowed for surface dry for 2-3 hours and then the $\mathrm{W}_{\text {saturated was }}$ recorded.

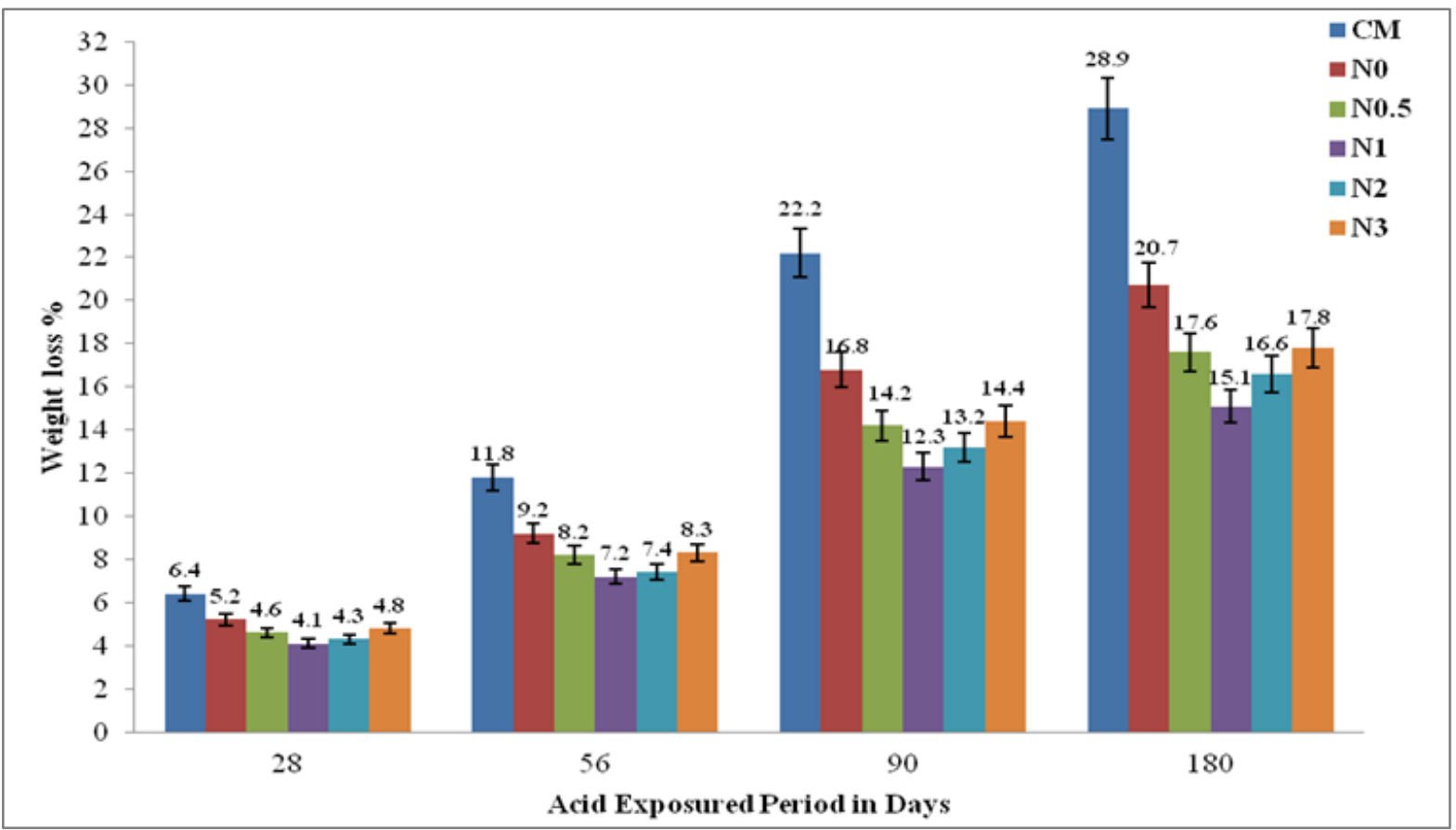

Figure 2. Weight loss of TBC - M30 grade

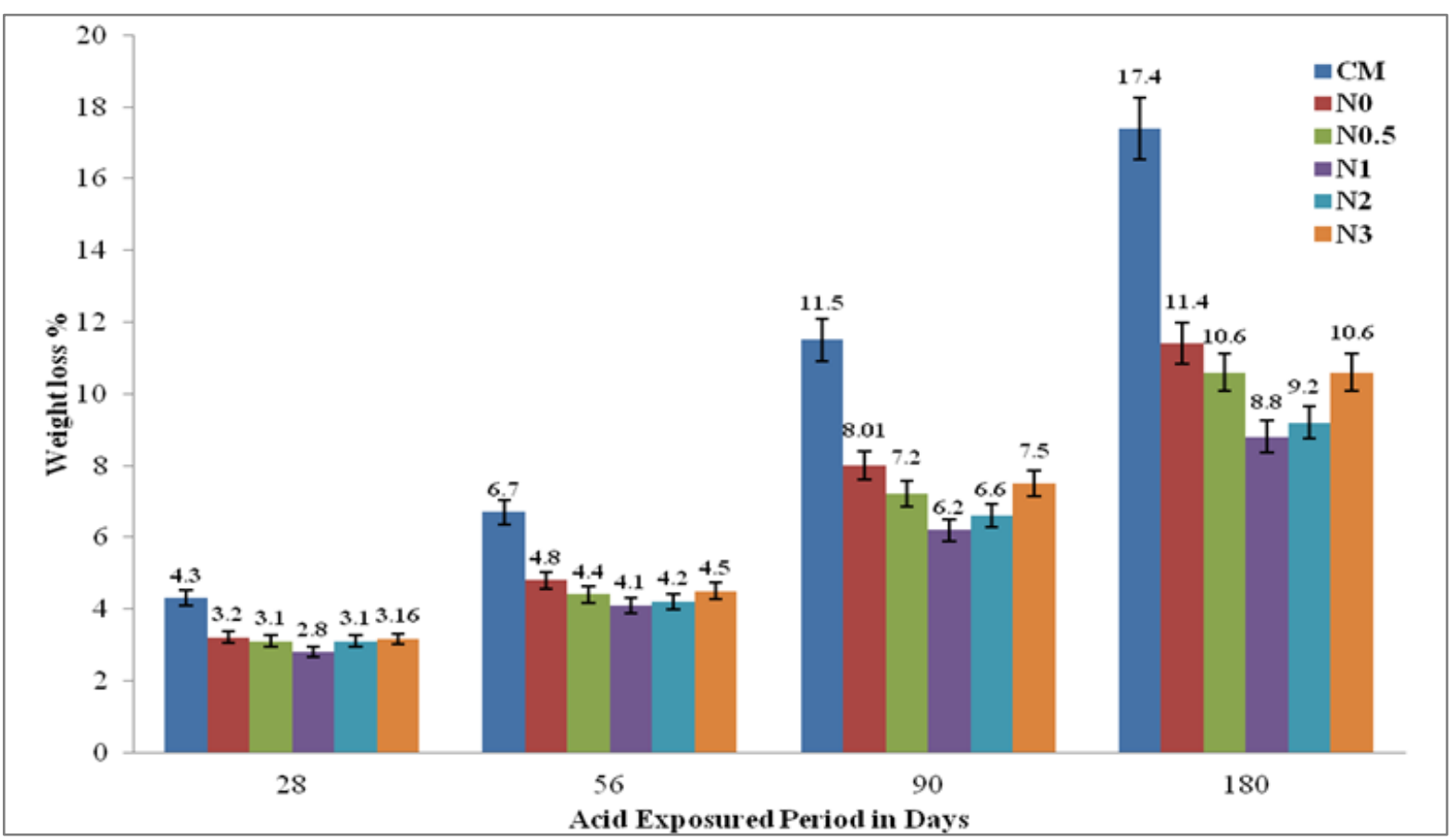

Figure 3. Weight loss of TBC - M60 grade 
From the results, it is seen that the incorporation of a combination of different micro and nanoparticle sized admixtures in the concrete of M30 and M60 grades shows improvement to acid resistance at all the stages for all the proportions. The fig. 2 and fig. 3 show the graphical representation of the weight loss of TBC specimens compared with conventional concrete for both $\mathrm{M} 30$ and M60 grade of concrete. From the results, it is found that the longer exposure to aggressive acid the more the weight loss for all specimens. The weight loss for conventional concrete is maximum compared to the weight loss of all other mixtures, which is $6.4 \%, 11.8 \%$, $22.2 \%$ and $28.9 \%$ for M30 grade, for M60 grade it was $4.3 \%, 6.7 \%, 11.5 \%$ and $17.4 \%$ for $28,56,90$, for 180 days of acid exposure. The weight loss of the TBC specimens containing a combination of $25 \% \mathrm{FA}, 10 \% \mathrm{AL}$ and $1 \%$
NS is minimum compared to the weight loss of all other mixtures, it was about $4.1 \%, 7.2 \%, 12.3 \%$ and $15.01 \%$ for M30 grade, for M60 it was 2.8\%, 4.06\%, $6.1 \%$ and $8.8 \%$ for 28, 56, 90 and 180 days of acid exposure. It is seen that all the TBC mixes showed a less weight loss when compared with conventional concrete in both M30 and M60 grades of concrete. This indicates that the incorporation of a combination of $\mathrm{FA}, \mathrm{AL}$, and $\mathrm{NS}$ in TBC helps in preserving its microstructure and improves resistivity to acid attack. The fig. 4 and fig. 5 represent the percentage of resistance to acid by TBC mix when compared with conventional concrete. It was determined by using the formula Weight loss percentage $=(($ Weight loss by traditional concrete specimen - Weight loss by specimen containing different percentages of NS) / (Weight loss by traditional concrete specimen)) $\mathrm{x} 100$.

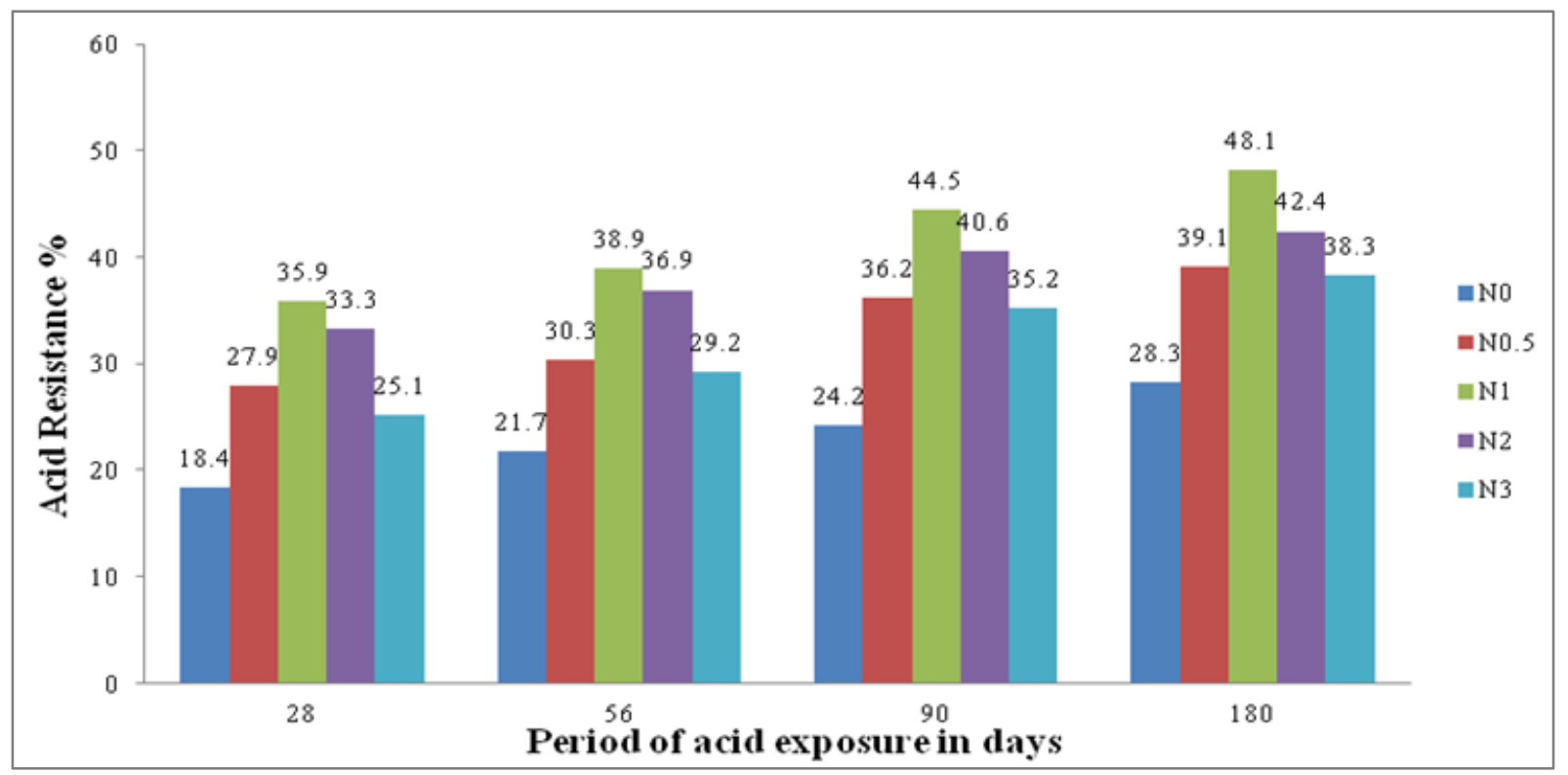

Figure 4. Resistance percentage of TBC vs. Period of acid exposure for M30 grade of concrete

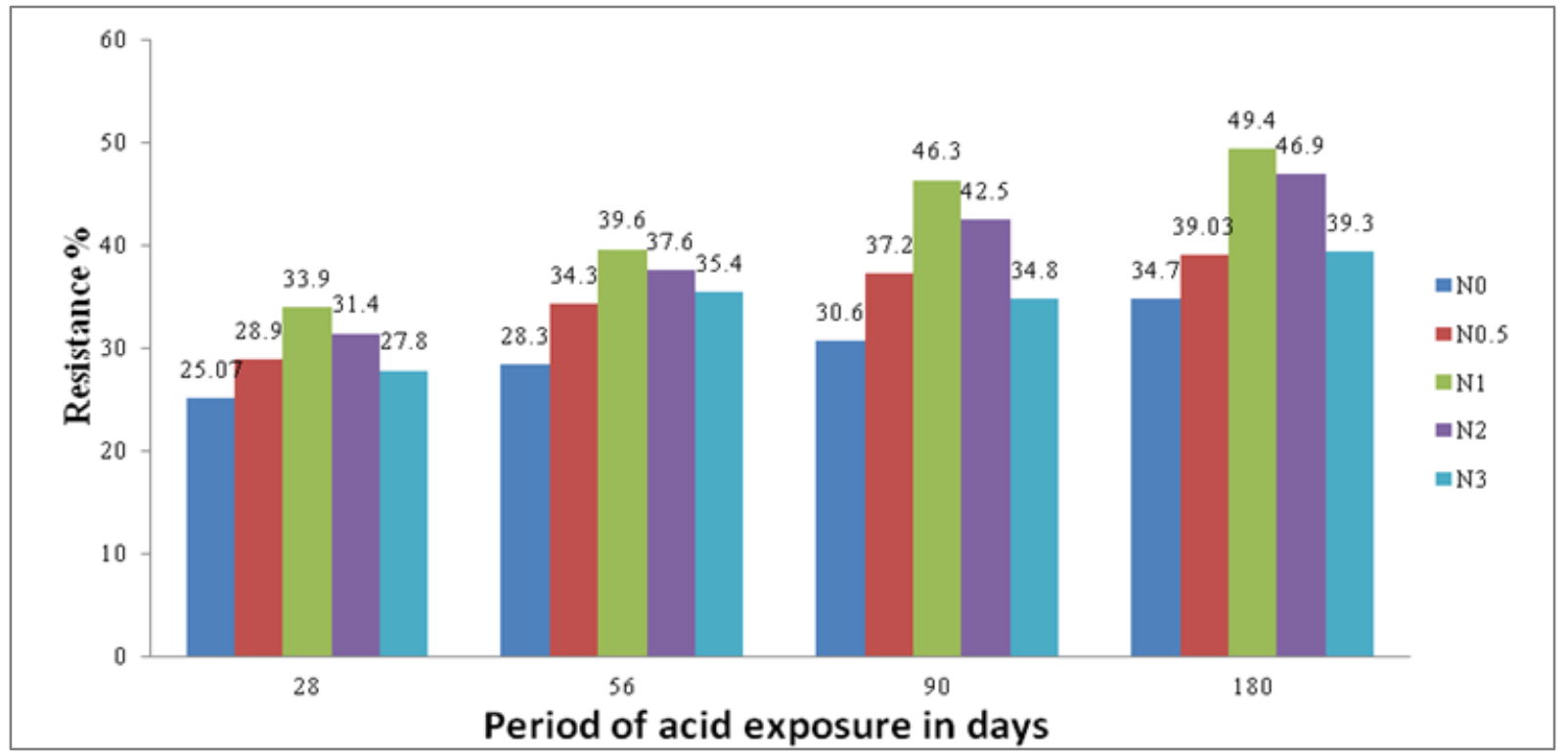

Figure 5. Resistance percentage of TBC vs. Period of acid exposure for M60 grade of concrete 
From the fig. 4 and fig. 5, it is seen that the maximum acid exposure resistance percentage was observed by N1 mix with $35.9 \%, 38.9 \%, 44.5 \%, 48.1 \%$ for M30 grade, $33.9 \%, 39.6 \%, 46.3 \%$, and $49.4 \%$ for M60 grade at 28,56 , 90 and 180 days acid exposure when compared with conventional concrete. From the result, it is seen that the TBC mix containing a combination of $25 \% \mathrm{FA}, 10 \% \mathrm{AL}$, and $1 \%$ NS showed the best acid resistance percentage due to the homogeneous form of a cementitious matrix where micro and nanoparticles helped in filling the voids in the concrete. As the NS percentage increases beyond $1 \%$, the resistance against acid tends to decrease for all the exposure periods which may be due to the excess amount of NS which will leach out during the hydration process affecting the pore structure of the concrete leading to the formation of more pores which impedes the permeation of acid solution resulting in more leaching out of $\mathrm{Ca}(\mathrm{OH})_{2}$ causing more weight loss of specimen $[1,5,13,27]$.

\section{Conclusions}

The test results showed that the conventional concrete mix yields the highest weight loss when compared to all other TBC mixes. The weight loss increased as the duration of acid exposure increased. The minimum weight loss has occurred in the N1 mix (25\% FA, $10 \% \mathrm{AL}$, and $1 \%$ NS) for both M30 and M60 grade of TBC concrete mix when compared with all other concrete mixes. The results also revealed that the combined effect of micro and nanoparticles not only acts as a filler material but also helps in improving the hydration process that resulted in a formation of denser pore structure and fewer pore voids. As a result, less damage occurs in the matrix after immersion in acid solution and thereby decreases mass loss percentage in the TBC specimens and enhanced the acid resistance. From the result, it can be concluded that the ternary blended concrete with the combination of fly ash, alccofine, and nanosilica is assessed to be acid-resistant and can be used for construction purposes in acidic environments.

\section{REFERENCES}

[1] Nandhini, K., and V. Ponmalar. "Investigation on nano-silica blended cementitious systems on the workability and durability performance of self-compacting concrete," Materials Express, Vol. 10, No.1, pp.10-20, 2020.

[2] Mahmoud, M. H., and M. T. Bassuoni. "Performance of Concrete with Alkali-Activated Materials and Nanosilica in Acidic Environments," Journal of Materials in Civil Engineering, Vol. 31, No. 3, pp.1-9, 2019.

[3] Walzade, Swapnil B., and Noorina Tarannum. "Influence of Colloidal Nano- $\mathrm{SiO}_{2}$ on durability properties of high strength concrete," International Research Journal of Engineering and Technology, Vol.3, No.8, pp 1277-1281, 2016.

[4] Supit, Steve Wilben Macquarie, and Faiz Uddin Ahmed Shaikh. "Durability properties of high volume fly ash concrete containing nano-silica," Materials and structures, Vol. 48, No.8, pp. 2431-2445, 2015.

[5] P. R. Kalyana Chakravarthy and R. Rathan Raj, "Analysis on compressive strength of concrete with partial replacement of cement with nano silica," ARPN Journal of Engineering and Applied Sciences, Vol. 12, No. 8, pp. 153-161, 2017.

[6] Zhang, M.H. and Li, H., Pore structure and chloride permeability of concrete containing nano-particles for pavement, Construction and Building Materials, Vol. 25, pp. 608-616, 2011.

[7] ASTM C494: 2017, "American Standard specification for chemical admixture for concrete", West Conshohocken, USA, 2017.

[8] ACI 211.4R: 2008, “American Concrete Institute Standard specification for mix design for concrete", West Conshohocken, USA, 2008.

[9] E. Gartner, "Industrially interesting approaches to 'Low- $\mathrm{CO}_{2}$ cement", Cement and Concrete Research, Vol. 34, No. 9, pp. 1489-1498, 2004.

[10] Malhotra, V., "Introduction: Sustainable development and concrete technology", Concrete Intelligence, Vol.24, No. 7, pp. 235-242, 2002.

[11] Moncarz. P, "Sustainable concrete: impacts of existing and emerging materials and technologies on the construction industry". Architectural Engineering Conference, June 19-20, 2011.

[12] Suhendro. B, "Toward green concrete for a better sustainable environment," Procedia Engineering, Vol. 95, pp. 305-320, 2014.

[13] P. Kathirvel, V. Saraswathy, S. P. Karthik, and A. S. S. Sekar, "Strength and durability properties of quaternary cement concrete made with fly ash, rice husk ash and limestone powder," Arabian journal of science and technology, Vol. 38, pp. 589-598, 2012.

[14] Temuujin. J, Van Riessen. A, MacKenzie. K, "Preparation and characterization of fly ash-based geopolymer mortars," Construction and Building Materials, Vol. 24, No. 10, pp. 1906-1910, 2010.

[15] Worrell. E, Price. L, Martin. N, Hendriks. C, Meida. L.O, "Carbon-dioxide emissions from the global cement industry", Annual Review of Environment and Resources, Vol. 26, No.1, pp. 303-329, 2001.

[16] Bhuvaneshwari, B., Sasmal, S., Baskaran, T. and Nagesh, R.I., "Role of nano oxides for improving cementitious building materials," Journal of Civil Engineering and Science, Vol. 1, pp. 52-58, 2012.

[17] IS 10262: 2009, "Indian standard code of practice for Concrete Mix Proportioning-Guidelines," New Delhi, India, 2009.

[18] IS 12269: 2013, "Indian standard code of practice for Ordinary Portland Cement 53 grade-specification," New 
Delhi, India, 2013.

[19] IS 383: 2016, "Indian standard code of practice for Specification for Coarse and Fine Aggregates from Natural Sources for Concrete," New Delhi, India, 2016.

[20] IS 561: 1959, "Indian standard code of practice for Methods of Tests for Strength of Concrete", New Delhi, India, 1959.

[21] IS 3812: 2013, "Indian standard code of practice for Pulverized fuel ash - specification, part 1 for use as pozzolana in cement, cement mortar and concrete," New Delhi, India, 2013.

[22] IS 456: 2000, "Indian standard code of practice for Plain and Reinforced Concrete - Code of Practice is an Indian Standard code of practice for general structural use of plain and reinforced concrete", New Delhi, India, 2000.

[23] Lincy, V., Rao, V.V.L.K. and Lakshmy, P., “A Study on Nanosilica and Microsilica Concretes under Different Transport Mechanisms," Magazine of Concrete Research, Vol.70, No. 23, pp. 1205-1216, 2018.

[24] Khanzadi, M., Tadayon, M., Sepehri, H and Sepehri, M., "Influence of Nanosilica particles on Mechanical Properties and Permeability of Concrete", $2^{\text {nd }}$ International Conference on Sustainable Construction Materials and Technologies, Ancona, Italy, 2010.

[25] Isfahani, F.T., Redaelli, E., Li, W. and Sun, Y., Effects of Nanosilica on Early Age Stages of Cement Hydration,
Journal of Nanomaterials, 2017, Vol. 24, pp. 1-9.

[26] Hou, P., Kawashima, S., Kong, D., Corr, D.J., Qian, J. and Shah, S.P., "Modification Effects of Colloidal Nanosilica on Cement Hydration and its Gel Properties," Composites Part B: Engineering, Vol. 45, pp. 440-448, 2013.

[27] Chithra, S., Senthil Kumar, S.R.R. and Chinnaraju, K, "The effect of Colloidal Nano-silica on workability, mechanical and durability properties of High-Performance Concrete with Copper slag as partial fine aggregate," Construction and Building Materials, Vol. 113, pp. 794-804, 2016.

[28] ASTM C989-1999, “American Standard specification for Standard Specification for Ground Granulated Blast-Furnac e Slag for Use in Concrete and Mortars," West Conshohocken, USA, 1999.

[29] Mochamad Solikin, Alfian Nur Zaini, Budi Setiawan, Ali Asroni , "Flexural Strength Analysis of Styrofoam Concrete Hollow Panel Walls Incorporated with High Volume Fly Ash," Civil Engineering and Architecture, Vol. 8, No. 3, pp. 320 - 325, 2020. DOI: 10.13189/cea.2020.080316.

[30] Dalia Elghezanwy, Sara Eltarabily, "A Review of Translucent Concrete as a New Innovative Material in Architecture," Civil Engineering and Architecture, Vol. 8, No. 4, pp. 571 - 579, 2020. DOI: 10.13189/cea.2020.080421.

[31] Haseeb Jamal, "Concrete Technology - Acid Attack on Concrete", Concrete Technology, https://www.aboutcivil.or $\mathrm{g} /$. 